\title{
UK and Twenty Comparable Countries GDP-Expenditure- on-Health 1980-2013: The Historic and Continued Low Priority of UK Health-Related Expenditure
}

\author{
Andrew J.E. Harding*, Colin Pritchard
}

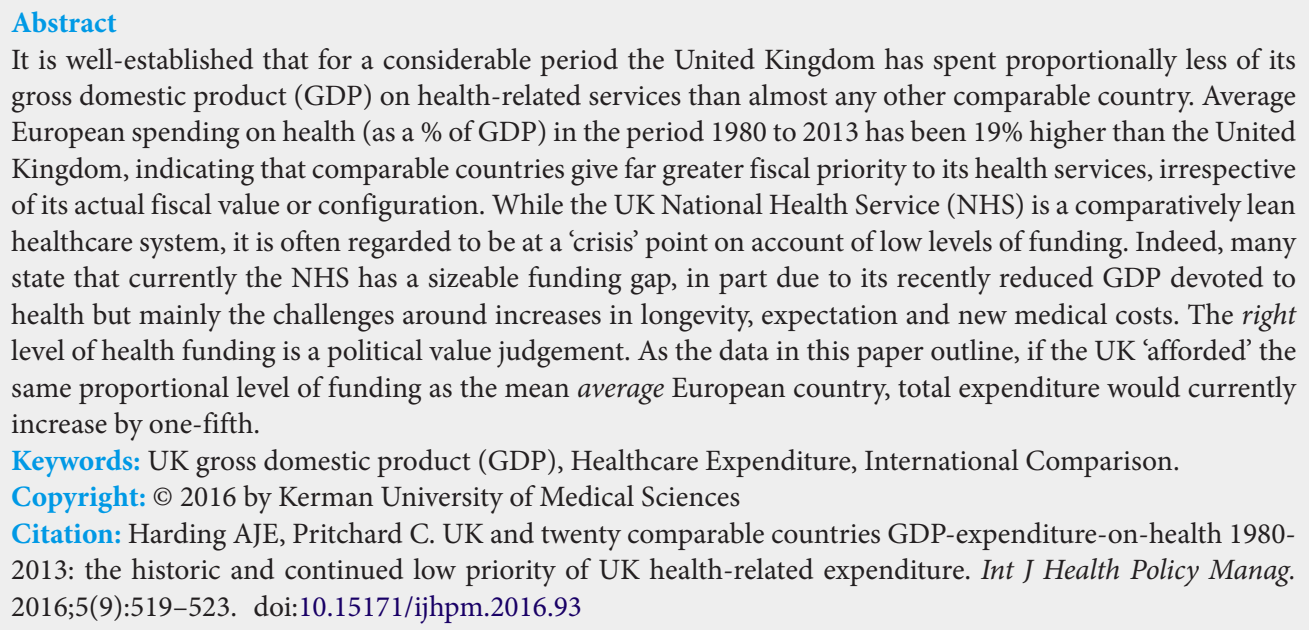

It is well-established that for a considerable period the United Kingdom has spent proportionally less of its gross domestic product (GDP) on health-related services than almost any other comparable country. Average European spending on health (as a \% of GDP) in the period 1980 to 2013 has been 19\% higher than the United Kingdom, indicating that comparable countries give far greater fiscal priority to its health services, irrespective of its actual fiscal value or configuration. While the UK National Health Service (NHS) is a comparatively lean healthcare system, it is often regarded to be at a 'crisis' point on account of low levels of funding. Indeed, many state that currently the NHS has a sizeable funding gap, in part due to its recently reduced GDP devoted to health but mainly the challenges around increases in longevity, expectation and new medical costs. The right level of health funding is a political value judgement. As the data in this paper outline, if the UK 'afforded' the same proportional level of funding as the mean average European country, total expenditure would currently increase by one-fifth.

Keywords: UK gross domestic product (GDP), Healthcare Expenditure, International Comparison.

Copyright: $\odot 2016$ by Kerman University of Medical Sciences

Citation: Harding AJE, Pritchard C. UK and twenty comparable countries GDP-expenditure-on-health 19802013: the historic and continued low priority of UK health-related expenditure. Int J Health Policy Manag. 2016;5(9):519-523. doi:10.15171/ijhpm.2016.93

Article History:

Received: 24 November 2015

Accepted: 4 July 2016

ePublished: 10 July 2016

\section{Background}

As one introductory text on social policy states “...the amount governments spend on social policy can go up or down, depending on changing priorities." While some countries do not exercise complete control over social spending, recent political campaigns in the United Kingdom that have pledged to increase $e^{2}$ or decrease ${ }^{3}$ social spending indicate that levels of economic input reflect changing priorities.

On this basis, funding levels are one proxy of establishing the commitment of governments to social spending. Allowing for relative comparisons, this is commonly explored and expressed by establishing what proportion of gross domestic product (GDP) a country spends. ${ }^{1,4-6}$ While it is well-established that the UK government, when compared to other comparable countries, has for a long time spent a smaller proportion on and prioritised less of its GDP to health-related services, ${ }^{4-7} \mathrm{a}$ critical question in proportional terms is by how much? Why is this an important issue? The priorities of governments is an important area to investigate. All Western countries face similar challenges in relation to increases in longevity, expectation and new medical costs. ${ }^{8-10}$ However, in the United Kingdom, there are particular concerns about funding shortfalls for the National Health Service (NHS). ${ }^{7}$ Despite being one of the most cost-effective health systems in reducing adult mortality ${ }^{11}$ there are frequent indirect and direct concerns and dissatisfaction around whether levels of NHS funding can sustain the high quality to which it aspires. One example of an indirect dispute, but inextricably linked to levels of resources, concerns the recent junior doctors strike, while a more direct concern is epitomised by the excess of deaths in the Mid Staffs NHS Trust, which caused a national scandal. The resulting inquiry, the Francis Report, indicated that it was a distinct possibility that the trust "...did not have the resources and ability and failed to alert those responsible to the problem." 12 Reflecting these concerns, the retiring NHS Chief Executive Sir David Nicholson stated that it was "pretty clear in the NHS that there is a substantial financial problem, particularly in the hospital sector."13 Recent financial results supports these concerns. In the first half of the 2015-2016 financial year the NHS had a $£ 1$.6bn deficit, with a $£ 2.2 \mathrm{bn}$ deficit forecast for the end of the financial year. ${ }^{14}$

Amid the above concerns to the health and ability of the system to cope with increased demand, and such is the perceived need for extra funding, in November 2015 the UK government pledged an extra $£ 3$.8bn - or around a $4 \%$ increase on NHS England's $£ 101$ bn front line budget. This was reported to be part of the wider commitment for an increase in the annual NHS budget of $£ 8$ bn by $2020 .{ }^{15}$ Yet, recent analysis outlines that even these increases will fall short of adequately filing gaps in funding. ${ }^{7}$

As Mladovsky and colleagues outline, much of the political rhetoric and media narrative in the United Kingdom rarely highlights successes of the system and instead focuses on how the current configuration of services is unsustainable, running out of money and unaffordable. ${ }^{5}$ The economic input of any system can only be based on what can be afforded. The recent pledge by the 'leave' campaign to increase NHS funding by $£ 350 \mathrm{~m}$ per week upon Britain’s exit from the 
European Union (EU) indicates that an increase in funding may only be possible by de-prioritising other areas (though at the time of writing this pledge has been reneged). Indeed, as Appleby suggests, historically increases in NHS spending has been done by de-prioritising other areas of public policy. ${ }^{16}$ But, crucially, does the United Kingdom prioritise and 'afford' as much as other comparable countries?

The Blair government in the United Kingdom once outlined that, in order to meet the aforementioned challenges, a worthy policy objective should be to bring proportional health expenditure in line with the European average. ${ }^{17}$ Revisiting this proposal in the context of the contemporary concerns raised since (some of which are outlined above), what current additional proportional commitment would the United Kingdom need to make in order to reflect the proportional commitment made by comparable European countries?

Before addressing this question, it is important to be clear with the boundaries of what it is possible to claim, particularly in light of the configuration of different healthcare systems. When making national comparisons around fiscal priority in relation to health-related services, it must be acknowledged that the public-private configuration of health systems differs. On this basis, proportional comparisons around national fiscal commitments on health-related services must encompass whole systems (as opposed to isolating public expenditure), regardless of configuration.

While this whole systems approach provides a more robust and overall analysis, it triggers a question in the United Kingdom context around whether a low level of fiscal priority can solely be attributable to low levels public spending alone (and not low levels of private expenditure), and thus, whether it is reasonable to highlight and or call for increased public expenditure. While this may be a political question, it can be addressed robustly by examining attitudes towards healthcare configuration. This can determine whether there is a substantial desire for people to privately fund their own healthcare and, by implication, if it is credible to suggest low levels of funding could be made up from private sources. The NHS continues to be held in high regard by the British public, with $89 \%$ of respondents to a large British Social Attitudes survey supporting the principle of publicly funded healthcare through taxation and free at the point of use. ${ }^{18}$ Although reforms for nearly three decades have sought to allow private and third sector agencies to provide NHS funded services, ${ }^{19}$ in contrast, only approximately only $13 \%$ of UK citizens have solely private medical insurance. ${ }^{20}$ The high regard that the NHS has in public consciousness, and relatively low level of purely private coverage, suggests it is not credible to position private sources as making up any shortfall. Thus, it is reasonable to indicate from a political and public perspective that any increase in priority around healthrelated expenditure should come from public and not private sources.

\section{Methods}

Cross-referencing the percentage of comparable western countries gross-domestic-product expenditure on health (GDPEH) gives an indication of what priority and proportion of national income countries prioritise to funding healthrelated services. An Organization for Economic Co-operation and Development (OECD) dataset exists that illustrates different national GDPEH. ${ }^{21}$ However, it has many breaks on account of differences in methodology and even estimated values. However, more robust data is openly available.

The US Bureau of Statistics ${ }^{22}$ and The World Bank ${ }^{23}$ provide data on countries GDPEH from 1980 to 2013. Countries are ranked in Table by the highest average of GDPEH over the period and includes all sources of health-related funding from both public and private sources. The GDPEH average for 1980 up to 2013 comes from 24 separately reported years. Five countries did not have data for every year, and missing years are indicated in the table.

With the majority of expenditure coming from government sources in the United Kingdom, and questions of public spending, and thus, by implication healthcare spending, are issues that cannot be detached from politics. ${ }^{24}$ On this basis, the GDPEH results are grouped into three phases that cover different UK government periods of office (1980-1997, 1998-2010, and 2010-2013). Averages for these periods and overall averages are calculated to compare UK GDPEH with other comparable European countries. Ratios are also used to illustrate proportional differences in relation to GDPEH between the United Kingdom and European countries. The Unites States was not included in any meaningful comparisons as its very high GDPEH would distort any findings in comparison to the United Kingdom, hence the creation of a UK to Europe GDPEH ratio is a more modest comparison.

\section{Limitations}

Two aspects should be noted in relation to the clarity and limitations of this methodology. Firstly, although directly stated, the percentage differences in spending is not the core focus of this article. Instead the article focuses on the percentage difference in the priority and proportion of GDP spent on health. Secondly, and in relation to this, although each percentage national expenditure differs in amount (and thus, has a different numerator and denominator), calculating averages and using ratios serves to approximate proportional differences, as opposed to accurately represent them.

\section{Results}

The UK's GDPEH in 1980 was 5.6\% and ranked 19th out of the 21 countries for which data is available. By 1997 UK GDPEH rose to $6.7 \%$, but was the lowest of the 21 countries. Over the period 1980-1997, UK GDPEH averaged 6.2\%, or was ranked 20 th out of the 21 countries listed. In the same period, the 15 other European countries averaged $7.7 \%$, equating to a UK to Europe ratio of 1: 1.24. On this basis, as a percentage of GDP, European countries average healthcare expenditure was proportionally $24 \%$ higher than the United Kingdom.

From 1998 to 2010, UK GDPEH went from 6.7\% to $9.4 \%$. For the United Kingdom, 1998 to 2010 was the highest ever GDPEH commitment, averaging $7.9 \%$ over the period, compared to the European average of $9.1 \%$. This yields a UK to Europe ratio of 1.1.15, or in other words, European countries average healthcare expenditure was 15\% higher than the United Kingdom as a \% of GDP.

Over the final period from 2010-2013, UK GDPEH went from $9.4 \%$, down to $9.2 \%$ in 2011 , rose to $9.3 \%$ in 2012 and then decreased to $9.1 \%$ in 2013 . On this basis, the UK average 
Table. \% GDPEH 1980 -2013 (\% Rounded-up)

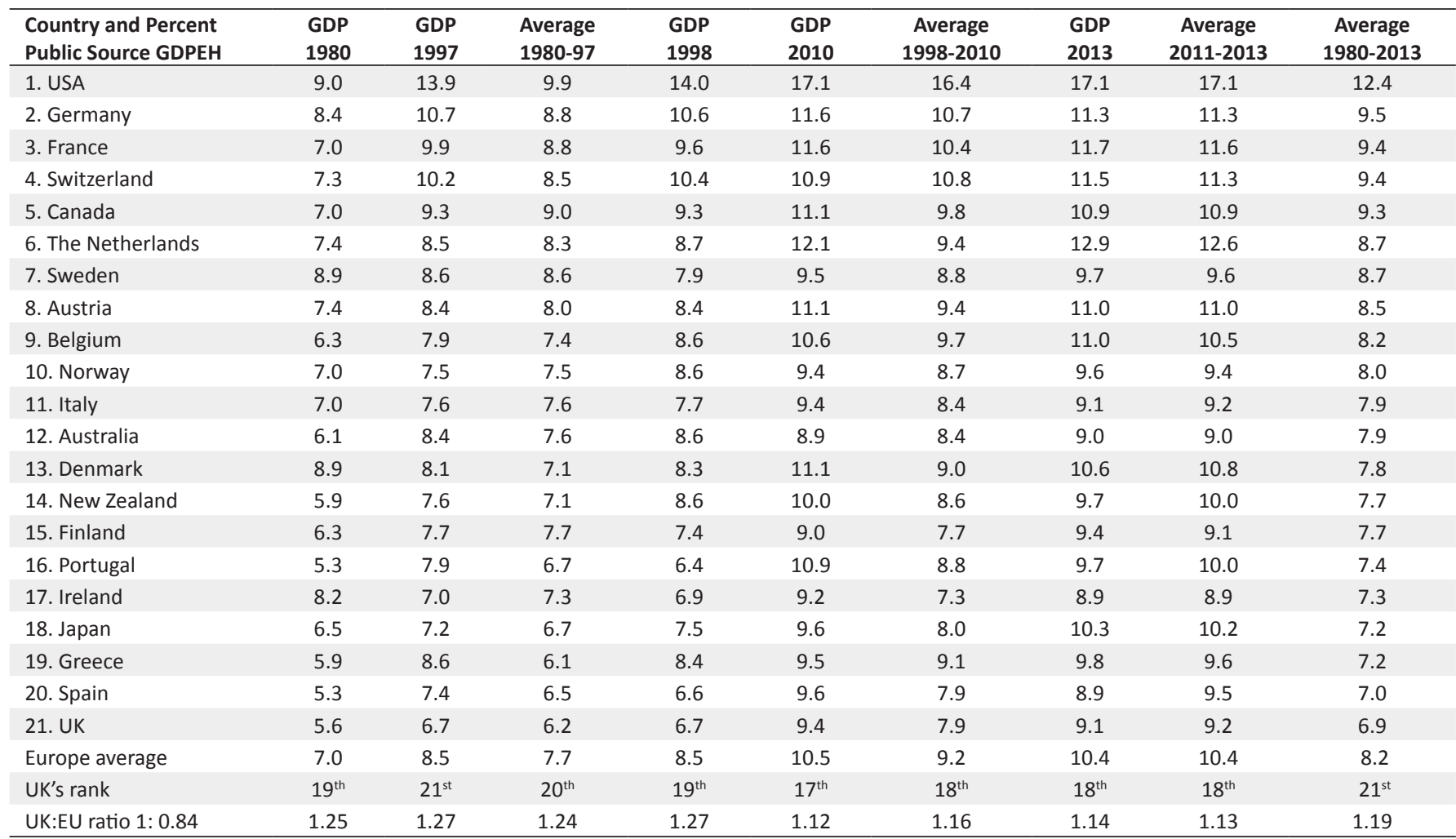

Abbreviations: GDPEH, gross-domestic-product expenditure on health; GDP, gross domestic product.

Correlating Rank Total GDPEH vs. Highest Public GDPEH Rho $=+0.3906, P<.05$

over the period was 9.2\%. When compared to the European average of $10.3 \%$, this data yields UK to European ratio of 1: 1.12 , indicating that recently European countries average healthcare expenditure was $12 \%$ higher than the United Kingdom as a \% of GDP during the period.

Over the whole period of 1980-2013, the UK GDPEH relative to other countries rose and fell but its overall average of $6.9 \%$ is the lowest in the GDPEH league table, followed by Spain at $7 \%$ and $7.2 \%$ for Greece and Japan.

Though the United Kingdom has narrowed the gap, which is attributable to the increases in proportional spending by the Blair government, recent years have seen UK GDPEH flat line. In other words, where once the United Kingdom was catching up, recent years indicate the proportional commitment relative to comparable European countries - is beginning to widen again.

The European average for the whole 1980-2013 period of $8.2 \%$ yields a UK to Europe ratio of 1: 1.19, thus, average European spending on healthcare as a \% of GDP in the period 1980 to 2013 has been approximately one-fifth higher, indicating a substantially greater priority given to its health services, irrespective of its real fiscal value or configuration. Interestingly, and of note, over the period the United States had the highest GDPEH, increasing from $9.0 \%$ in 1980 to $17.1 \%$ in 2013 . The United States 1980 -2013 average is $12.4 \%$, equating to a UK to US ratio of $1: 1.80$. Thus comparatively, the United States afforded approximately $80 \%$ more to healthcare expenditure than the United Kingdom as a \% of GDP.

Finally, it should be noted that, although every country increased its GDPEH considerably over the period, in some years a country reduced its level compared with the immediate preceding year. For example, the UK rate fell from the previous year's level in 1984, 1985, 1987, 1994, 1995, 2011, and 2013.

\section{Discussion}

With the most recent data illustrating the GDPEH commitment for 2013, this paper does not take into account the extra $£ 3.8$ bn annual increase pledged for England in November 2015 or the extra $£ 8$ bn a year to be committed from $2020 .{ }^{15}$ However, considering that there are over 140 English NHS providers for whom this money will be apportioned by NHS England, these increases are modest. Indeed, recent analysis outlines that these increases will still equate to a funding shortfall. ${ }^{7}$

Clearly in terms of commitment and priority to health funding, compared to other Western countries, over this period of over 30 years the United Kingdom is the least fiscally committed in the developed world. The fact that Britain's GDPEH fell from a high of 2010, at $9.4 \%$ and fell in 2011 and 2013, down to 9.1\%, perhaps reflects the wider and primary fiscal aim of austerity, ie, the well-publicised ambition to reduce the deficit. Hence, less of the rising national income, GDP, is being devoted to health than was previously.

Though partly attributable to low levels of spending, recent research finds that the NHS is regarded as the most efficient and cost-effective healthcare systems in the world. ${ }^{5}$ More specifically, in reducing adult (55-74) total mortality and cancer deaths, the United Kingdom had the second biggest reduction in 20 years and was one of the most cost-effective systems in the world. ${ }^{25,26}$ In addition, the United Kingdom met the UN Millennium goal of reducing child mortality, proving 
to be the eighth most cost-effective of Western countries. ${ }^{27}$ In other words, in these key areas the health services in the United Kingdom still achieves proportionally more with comparatively less.

In contrast to much political rhetoric and media narrative that focuses on the UK system as being unsustainable and unaffordable ${ }^{5}$ it is important to state unequivocally that the aforementioned figures can be seen as a vindication for the UK model of predominately publicly funded health ('free at the point of use' but funded mainly through taxation). On this basis, considering the effectiveness of the UK health system in relation to current economic input, and to counter the main position put forward in this paper and by others, ${ }^{5}$ the question must be asked whether there is actually a feasible a case to increase expenditure, possibly in line with the proportional commitments made European countries?

With many factors to consider, it is often not particularly helpful to refer to a health system as a single entity. Health systems have many components and are complex. Delving deeper, a case can be made that the aforementioned figures do not provide a full indication of system health status.

In addition, despite the aforementioned clinical achievements, as outlined earlier many NHS local Trust providers are currently running a large deficit which are forecast to increase further. ${ }^{14}$ This funding gap, according to a former NHS Chief Executive, will mean that NHS providers will struggle to meet the challenges of increased longevity and rising healthcare expectations faced by every Western country. ${ }^{13}$

Clearly then, there is a case to increase UK GDPEH. Yet, it is also important to note that increasing the financial commitment to healthcare is not necessarily a guarantee of using funds efficiently or effectively. Although inextricably linked, any recommendations are beyond the remit of this paper.

\section{Conclusion}

By a significant margin, the UK commits proportionally less of national income than all other comparable western countries. Furthermore, this is not a recent phenomenon brought on by contemporary austerity measures. Rather, the data outlines that this proportionally low level of financial commitment is an entrenched and established historical trend.

Many NHS providers are currently in deficit and financial difficulty. ${ }^{14}$ The data in this paper outlines that the fiscal context in which NHS providers operate is one, when compared to other European countries, of relative disadvantage.

But what is the right level of commitment? As noted elsewhere, to some extent this question is a political value judgement. ${ }^{4}$ However, if the United Kingdom had prioritised, afforded and committed the same proportional level of funding as the average European country, current total expenditure for the United Kingdom would be around onefifth higher. In the context of current and forecasted funding shortfalls in the NHS, ${ }^{7}$ an increase in funding to the European average would begin to address funding shortfalls. Echoing others $^{16}$ who have recently contributed to discussion in this area, if other comparable countries can make a larger proportional commitment and deem it affordable, in light of aforementioned challenges, why cannot the United Kingdom prioritise accordingly?
Ethical issues

Not applicable.

Competing interests

Authors declare that they have no competing interests.

Authors' contributions

Both authors contributed equally to the writing of this paper.

References

1. Dean H. Social Policy. 2nd ed. Polity Press; 2015.

2. Demianyk G. Michael Gove Promises Just $£ 100 m$ For NHS, and Dismisses Unpopularity in Bid for Tory Leadership. Secondary Michael Gove Promises Just £100m for NHS, and Dismisses Unpopularity in Bid for Tory Leadership. http://www.huffingtonpost.co.uk/entry/michael-gove-nhs_ uk_577641bae4b0c946080087b9. Published 2016.

3. Dominiczak P. Budget 2015: George Osborne slashes welfare but gives Britain a pay rise. The Telegraph. July 8, 2015. http:// www.telegraph.co.uk/finance/budget/11727751/Budget-2015George-Osborne-slashes-welfare-but-gives-Britain-a-pay-rise. html.

4. Dixon J, Harrison B, New B. Funding the NHS. Is the NHS underfunded? BMJ. 1997;314:58. doi:10.1136/bmj.314.7073.58

5. Mladovsky P, McKee M, Ingleby D, Rechel B. Greater public investment is needed to fund the NHS at a level considered normal in other high income countries. LSE Health and Social Care, London School of Economics; 2016.

6. Ingleby D, McKee M, Mladovsky P, Rechel B. How the NHS measures up to other health systems. BMJ. 2012;344:e1079. doi:10.1136/bmj.e1079

7. Roberts A, Thompson S, Charlesworth A, Gershlick B, Stirling A. Filling the Gap: Tax and Fiscal Options for a Sustainable UK Health and Social Care System. London: The Health Foundation; 2015.

8. Faden RR, Chalkidou K, Appleby J, Walters HR, Leider J. Expensive cancer drugs: A comparison between the United States and the United Kingdom. Milbank Q. 2009;87:789-819. doi:10.1111/j.1468-0009.2009.00579.x

9. Department of Health. Improving Outcomes: A Strategy for Cancer. London: Department of Health; 2011.

10. Jonsson L, Justo NM, Krinshna A, et al. Cost of treatment in patients with metastatic soft tissue sarcoma who respond favourably to chemotherpy. The SArcoma treatment and Burden of Illness in North America and Europe (SABINE) study. Eur J Cancer Care (Engl). 2015;25(3):466-477. doi:10.1111/ecc.12322

11. Pritchard $C$, Hickish $T$, Rosenorn-Lanng $E$, Wallace $M$. Comparing UK and 20 Western countries' efficiency in reducing adult (55-74) cancer and total mortality rates 1989-2010: Cause for cautious celebration? A population-based study. JRSM Open. 2016; Forthcoming. doi:10.1177/2054270416635036

12. Francis R. Report of the Mid Staffordshire NHS Foundation Trust Public Inquiry. London: The Stationary Office; 2013.

13. Dreaper J, Triggle N. NHS finance problem being ignored, says former boss. Secondary NHS finance problem being ignored, says former boss. http://www.bbc.co.uk/news/ election-2015-32325490. Published 2015.

14. Campbell D. NHS deficit soars to £1.6bn. The Guardian. November 20, 2015. https://www.theguardian.com/society/2015/ nov/20/nhs-deficit-soars-to-16bn.

15. Triggle N. NHS to get above-inflation $£ 3.8 \mathrm{bn}$ cash boost next year. Secondary NHS to get above-inflation $£ 3.8 \mathrm{bn}$ cash boost next year. http://www.bbc.co.uk/news/health-34905801. Published 2015.

16. Appleby J. How does NHS spending compare with health spending internationally? Published 2016. 
17. Watt N. Blair's £12bn pledge to NHS. The Guardian. 2000. https:// www.theguardian.com/society/2000/jan/17/futureofthenhs. health1.

18. Gershlik B, Charlesworth A, Taylor A. Public Attitudes to the NHS: An analysis of responses to questions in the British Social Attitudes Survey. London: The Health Foundation and National Centre for Social Research; 2015.

19. Harding AJE, Sanders F, Medina Lara A, et al. Patient Choice for Older People in English NHS Primary Care: Theory and Practice. ISRN Fam Med. 2014;2014: 742676. doi:10.1155/2014/742676

20. Healthcare Choices: NHS versus Private. YouGov website. https://yougov.co.uk/news/2013/06/17/healthcare-choices-nhsversus-private/. Published 2013.

21. The Organisation for Economic Co-operation and Development (OECD). OECD Health Statistics 2015. Published 2015.

22. US Bureau of Statistics. Statistical Abstract of the United States. Secondary Statistical Abstract of the United States 2014. http://www2.census.gov/library/publications/2011/compendia/ statab/131ed/tables/12s1346.xls
23. The World Bank. Health expenditure, total (\% of GDP). Secondary Health expenditure, total (\% of GDP). http://data. worldbank.org/indicator/SH.XPD.TOTL.ZS. Published 2015.

24. Bambra C, Fox D, Scott-Samuel A. Towards a politics of health. Health Promot Int. 2005;20(2):187-193. doi:10.1093/heapro/ dah608

25. Pritchard C, Hickish T. Comparing cancer mortality rates in England \& Wales with other major developed countries 19792006. Br J Cancer. 2011;105(11):1788-1794. doi:10.1038/ bjc. 2011.393

26. Pritchard C, Wallace MS. Comparing the USA, UK and 17 Western countries' efficiency and effectiveness in reducing mortality. JRSM Short Rep. 2011;2(7):60. doi:10.1258/ shorts.2011.011076

27. Pritchard C, Wallace MS. Comparing UK and other Westerns countries' health expenditure, relative poverty \& child mortality. Are British children doubly disadvantaged? Child Soc. 2015;29(5):462-472. doi:10:111/chso.12079 